\title{
NONLINEAR REGRESSION APPLICATIONS IN MODELING OVER-DISPERSION OF BIRD POPULATIONS
}

\author{
E. Çelik ${ }^{1}$ and A. Durmuş ${ }^{2}$ \\ ${ }^{1}$ Igdir University, Vocational School of Technical Sciences, Department of Forestry/Hunting and Wildlife Program \\ 76000 IGDİR, Turkey; ${ }^{2}$ Yuzuncu Y11 University Faculty of Sci. and Let., Department of Biology 65080 VAN, Turkey \\ Corresponding Author's E-mail: celikemrah822@gmail.com
}

\begin{abstract}
The aim of this study was to statistically evaluate bird populations in Akdoğan Lakes by means of Poisson and negative binomial regression models. The over-dispersion value in Poisson regression was much higher than 1.0 (33.827). In contrast, the value of over-dispersion in the negative binomial regression was very close to 1.0 (1.598). Therefore, the parameter estimates were interpreted considering the negative binomial regression. When spring season was considered as a reference parameter, the change in population densities in other seasons was not statistically significant. The population changes in other habitats were not statistically significant, when reed area was considered as a reference parameter. The change in the population density of 13 ordo groups is non significant when the Anseriformes order was evaluated as reference parameter. The population change in the Gruiiformes population was 11.951 times higher compared with the change in reference parameter and the change was statistically significant $(\mathrm{p}<0.01)$.

As a result, it is recommendable to use negative binomial regression with the scope of removing over-dispersion problem in the bird population modeling.
\end{abstract}

Keywords: Akdoğan (Hamurpet) Lakes, Over-disperison, Bird populations, Negative binominal regression, Poisson regression.

https://doi.org/10.36899/JAPS.2020.2.0054

Published online March 02, 2020

\section{INTRODUCTION}

Determining the habitat preferences of living species and predicting the abundance of habitat are important steps of ecological studies (Joseph et al., 2009; O'Hara and Kotze, 2010). Prediction of populations is very essential at the basis and practice of ecology (Yoccoz et al., 2001). Revealing the impacts of habitat variables on the distribution and habitat preferences of living species is imperative to investigate and describe the distributions of living organisms (Özkan, 2009; Adizel et al., 2010; Aksan et al., 2014;). Many biotic and abiotic factors such as vegetation structure (Stanevičius, 2002; Milsom et al., 2000), human activities (Milsom et al., 2000; Yuan et al., 2014), temperature, precipitation and humidity (Seoane et al., 2004; Beerens et al., 2011) may affect the distribution of living organisms (Geldiay and Kocataş, 1983).

Habitat is of the major factors influencing the dsitribution of bird species and their population in a certain area (Bibby et al., 2000; Çelik and Durmuş, 2017). Also, the distribution of most bird species shows some degree of grouping. There are, for example, colonyforming species during migration and reproduction, as well as non-colony species that use the area solely for feeding and resting purposes (Bibby et al., 2000). The differences are mainly based on their habitat preference. Moreover, many ecological factors affect the habitat preference and geographical distribution of birds. (Beerens et al., 2011; Austin et al., 2014). These factors affect the ecological and physiological demands of birds and consequently affect their distribution.

As bioindicator creatures of natural ecosystem, birds have significant contributions to biological diversity according to their habitat preferences and population densities (Kiziroğlu, 2001; 2008). Therefore, the more the habitat preferences distribution of birds in habitats, the naturalness and biodiversity of that area can be increased. The most common technique used to identify bird populations is the counting (Bibby et al., 2000). Independent data obtained based on counting can show Poisson distribution (PD) and analyzed by Poisson regression (PR) (Ridout, 1998). The basic principle of PD is that the mean and variance are equal. However, count data do not always support this distribution in real cases (Leisch, 2004; Muthen and Muthen, 2006; SAS, 2014). Over-dispersion occurs where the variance is greater than the mean (Ver Hoef and Boveng, 2007; SAS, 2015). Alternative suitable models such as quasi-likelihoodbased poisson models (Wedderburn, 1974), randomeffects models (Bolker et al., 2008; O'Hara, 2009), binomial mixture model (Boveng et al., 2003; Mathews and Pendletan, 2006) poisson regression (Yeşilova et al., 2016), generalized poisson regression (Famoye and Karan, 2006; Czado et al., 2007) are available for modeling over-dispersion in the data set (Wang et al., 
1996; Wang and Putterman, 1998; Dalrymple et al., 2003). Negative binomial regression is one of the methods to overcome the effect of over-dispersion (Agresti, 1997; Hilbe, 2007; Yeşilova et al., 2010). Examples of negative binomial regression are obtainable in many different studies. Negative binomial regression model has been used in identification of species richness (O'Hara, 2005), parasites in birds (Rekasi et al., 1997) and intensities of bird population (White and Bennetts, 1996; Durmuş et al., 2018), determination of environmental variables affecting the migratory phenomenon of birds (Lindén and Mantyniemi, 2011) and estimation of the direction and abundance parameters of waterfowl (Frost et al., 1999; Small et al., 2003).

Of those methods, poisson regression and negative binom regression were fitted to the data of the present study. Therefore, we herein applied nonlinear regressions including poisson regression and negative binom regression. Along with the results of study, there will be contribution to literature regarding with population based distribution of birds using plausible alternative statistical modeling. There are limited studies performed on the uses of those regression models. In literature, the changes in species and population corresponding to the habitat and season have not yet been reported for bird population modeling. Therefore, this study aimed to apply nonlinear regressions in modeling over-dispersion of bird populations based on counting in
Akdoğan (Hamurpet) Lake from Eastern Anatolia Region, Turkey.

\section{MATERIALS AND METHODS}

The materials of this study are Akdoğan (Hamurpet) Lakes (37 S 736800, 4335867) located in the Eastern Anatolia, Turkey and birds that using the lakes for living purposes. Observations to determine the population density were performed by 15 -day periods within each month between April 2016 and September 2017. Numerical data were obtained with an 18 -month field study covering 3 seasons. Observations, depending on seasonal conditions, have started with sunrise and ended with sunset. The study area was divided into 66 $1 \mathrm{x} 1 \mathrm{~km}^{2}$ UTM square grids (Figure 1). Three observation points at least 300 meters apart from each other were selected in each UTM square to represent the habitats found on the surface. Methods of observation along line transect and point counts were used in observation of population density and number of individuals (Bibby and Burgess, 2000). Bird species, population numbers and UTM coordinates detected at and around the observation point were recorded on field observation cards. The records obtained at each observation point were then assigned to grids and used. This process enabled analysis of data on a grid basis besides point scale (Onmus, 2008).

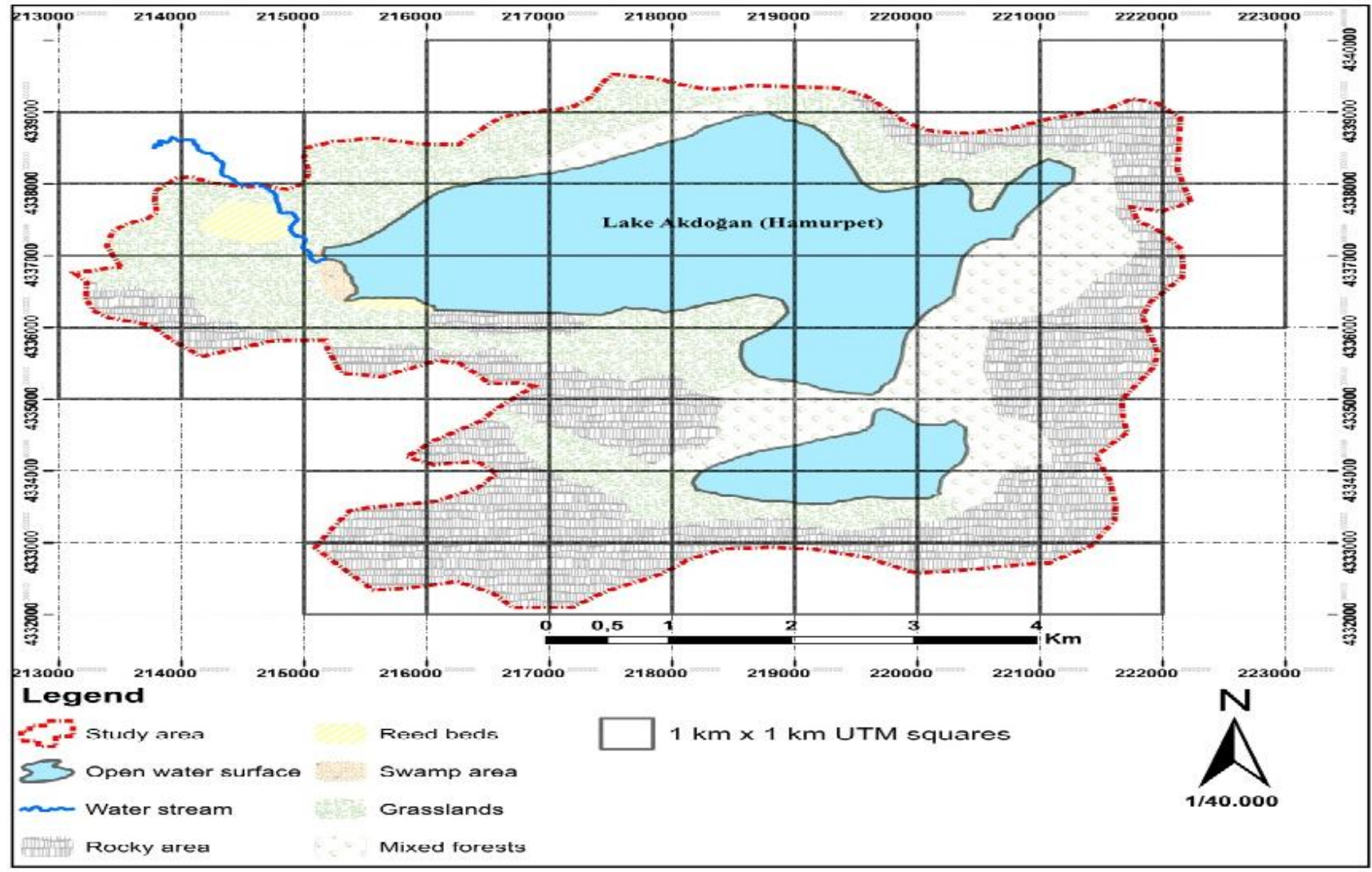

Fig. 1. Map of the study area divided into $1 \times 1 \mathrm{~km}^{2}$ UTM squares 
Statistical Analyses: Poisson regression is often used to analyze dependent variables based on count data. The main characteristic of Poisson distribution is the assumption that the mean and variance are equal. Variance is higher than the mean in most cases and this is called over-dispersion. The over-dispersion is usually encountered in data sets and the use of Poisson regression causes deviation parameter estimates and standard errors. The deviance statistic value of $>1.0$ indicates overdispersion in the bird population.

In the study, bird population data were dependent variables, and seasons, habitats, orders, number of species and grids were taken as independent variables Table 1.

Poisson regression: Poisson regression assumes that the dependent variable which is the observed event number ( $\mathrm{y}_{\mathrm{i}}$ ), has a Poisson distribution. The logarithm of Poisson mean $(\mu)$ is assumed to be a linear function of the independent variables (Yeşilova et al 2016). In the Poisson regression, parameter estimation is obtained by the maximum likelihood estimation (ML) method. Likelihood function for nonlinear PR model can be written as follow;

Table 1. Variables used in the study.

\begin{tabular}{lcc}
\hline Variables & $\begin{array}{c}\text { Dependent } \\
\text { variables }\end{array}$ & $\begin{array}{c}\text { Independent } \\
\text { variables }\end{array}$ \\
\hline Species & & + \\
Orders & + & + \\
Population & & + \\
Season & & + \\
Habitat & & + \\
Grid & & \\
\hline
\end{tabular}

$$
\ln L=\sum_{i=1}^{n}\left[-\lambda_{i}+y_{i} x_{i}^{\prime} \beta-\ln y_{i} !\right]=\sum_{i=1}^{n}\left[-e^{\mathbf{x}_{i}^{\prime} \beta}+y_{i} x_{i}^{\prime} \beta-\ln y_{i} !\right]
$$

Negative binomial regression: Negative binomial regression model can be given as follow (Hilbe 2007). k in equation is an auxiliary parameter indicating the extent of over-dispersion and $\mathrm{k}$ is taken as a positive value.

$$
P\left(Y=y \mid X_{1}, X_{2}, X_{3}, k\right)=\frac{\Gamma(y+k)}{\Gamma(k) \Gamma(y+1)}\left(\frac{k}{k+\mu}\right)^{k}\left(\frac{\mu}{k+\mu}\right)^{y} \quad y=0,1,2, \ldots
$$

The statistical analyzes were performed using SAS 9.1.1.4 statistical software (Ver Hoef and Boveng, 2007). Since data account for over-dispersion of population, SAS software package is of the powerful statistical tools for analyzing the over-dispersion data where the variance is greater than the mean (Ver Hoef and Boveng, 2007; SAS, 2015).

\section{RESULTS AND DISCUSSION}

One hundred three species belonging to 14 orders and 33 families were recorded after approximately two-year of studies. Of the species, $36.9 \%(\mathrm{n}: 38)$ were local, $60.2 \%$ (n:62) were immigrants and $2.9 \%(\mathrm{n}: 3)$ were transit immigrants. Observations revealed that 9 of species were certainly breeding on the study area, 12 species were probably breeding on the region considering the courting behaviours and existance of male and female individuals, and 82 were not breeding on the study area. Five habitat types were identified as geographical, topographical and floristic within the boundaries of study area. Status of habitats and populations used by ordo groups were recorded during periodic observations made through 3 seasons (Table 2). Winter observations have not been conducted because roads leading to the area were closed due to the harsh and rainy winter conditions in the region.

Table 2. Population intensities, seasonal habitat distributions and UTM square numbers of orders in Akdoğan (Hamurpet) Lakes.

\begin{tabular}{cccccc}
\hline Ordo & Number of Species & Population Density & Seasons & Habitat Type & Square \\
\hline 101 & 6 & 69 & 11 & 3 & 7 \\
101 & 1 & 20 & 11 & 5 & 7 \\
101 & 1 & 6 & 22 & 2 & 2 \\
101 & 1 & 13 & 22 & 5 & 1 \\
101 & 2 & 26 & 33 & 2 & 1 \\
\hline
\end{tabular}




\begin{tabular}{|c|c|c|c|c|c|}
\hline 102 & 1 & 10 & 22 & 5 & 2 \\
\hline 102 & 1 & 3 & 22 & 1 & 1 \\
\hline 103 & 1 & 1 & 22 & 5 & 1 \\
\hline 104 & 1 & 2 & 11 & 1 & 1 \\
\hline 104 & 4 & 229 & 11 & 2 & 10 \\
\hline 104 & 2 & 25 & 11 & 3 & 4 \\
\hline 104 & 2 & 11 & 11 & 4 & 2 \\
\hline 104 & 1 & 24 & 22 & 2 & 2 \\
\hline 104 & 6 & 87 & 22 & 4 & 4 \\
\hline 104 & 2 & 20 & 22 & 5 & 2 \\
\hline 104 & 2 & 35 & 33 & 2 & 3 \\
\hline 104 & 2 & 17 & 33 & 4 & 2 \\
\hline 104 & 2 & 45 & 33 & 5 & 2 \\
\hline 105 & 2 & 4 & 22 & 3 & 2 \\
\hline 106 & 2 & 73 & 22 & 5 & 4 \\
\hline 106 & 1 & 2 & 22 & 1 & 1 \\
\hline 106 & 1 & 8 & 33 & 5 & 2 \\
\hline 107 & 1 & 3 & 11 & 1 & 1 \\
\hline 108 & 1 & 2 & 11 & 1 & 2 \\
\hline 108 & 3 & 17 & 11 & 2 & 4 \\
\hline 108 & 2 & 8 & 11 & 2 & 3 \\
\hline 108 & 4 & 20 & 22 & 1 & 2 \\
\hline 108 & 5 & 76 & 22 & 2 & 4 \\
\hline 108 & 3 & 9 & 22 & 3 & 2 \\
\hline 108 & 10 & 53 & 22 & 5 & 2 \\
\hline 108 & 1 & 1 & 22 & 6 & 1 \\
\hline 109 & 4 & 181 & 11 & 3 & 6 \\
\hline 109 & 1 & 37 & 22 & 2 & 4 \\
\hline 109 & 1 & 199 & 22 & 3 & 5 \\
\hline 109 & 1 & 284 & 33 & 2 & 2 \\
\hline 110 & 2 & 37 & 11 & 1 & 2 \\
\hline 110 & 1 & 4 & 22 & 1 & 1 \\
\hline 111 & 14 & 191 & 11 & 1 & 25 \\
\hline 111 & 8 & 23 & 11 & 3 & 2 \\
\hline 111 & 7 & 519 & 11 & 5 & 32 \\
\hline 111 & 20 & 467 & 22 & 1 & 6 \\
\hline 111 & 2 & 2 & 22 & 3 & 1 \\
\hline 111 & 1 & 4 & 22 & 4 & 1 \\
\hline 111 & 28 & 743 & 22 & 5 & 9 \\
\hline 111 & 5 & 12 & 22 & 6 & 2 \\
\hline 111 & 14 & 188 & 33 & 1 & 8 \\
\hline 111 & 1 & 1 & 33 & 3 & 1 \\
\hline 111 & 1 & 2 & 33 & 4 & 1 \\
\hline 111 & 14 & 419 & 33 & 5 & 28 \\
\hline 111 & 6 & 21 & 33 & 6 & 4 \\
\hline 112 & 4 & 12 & 11 & 3 & 2 \\
\hline 112 & 1 & 2 & 22 & 3 & 1 \\
\hline 112 & 1 & 3 & 33 & 4 & 2 \\
\hline 113 & 1 & 23 & 11 & 2 & 3 \\
\hline 113 & 1 & 10 & 11 & 3 & 2 \\
\hline 113 & 2 & 25 & 22 & 2 & 2 \\
\hline 113 & 1 & 20 & 22 & 3 & 1 \\
\hline 113 & 2 & 46 & 33 & 2 & 5 \\
\hline 114 & 1 & 2 & 33 & 1 & 1 \\
\hline
\end{tabular}

Ordo: 101-Anseriformes, 102-Bucerotiformes, 103-Caprimulgiformes, 104-Charadriiformes, 105- 
Ciconiiformes, 106-Coraciiformes, 107-Cuculiformes, 108- Falconiformes, 109-Gruiformes, 110-Galliformes, 111-Passeriformes, 112- Pelecaniformes, 113Podicipediformes, 114-Strigiformes, Season: 11-Spring, 22-Summer, 33-Autumn, Habitat: 1-Rocky area, 2-Lake surface, 3-Reed area, 4-Swamp area, 5-Meadow area, 6Wooden area

Numerical data obtained in habitat-based observations were adapted to statistical analysis. Population density of the birds in the study area at order level, UTM square numbers used, population densities varying depending on the season and habitat structure are also revealed.
Statistical model: The bird population data obtained by counting are considered as model dependent variables. In addition, seasons, orders, habitat and squares were modeled as independent variables to model and Poisson and negative binomial regressions were applied, respectively.

The graph of bird counts considered as a model dependent variable is presented in Figure 2. The graph of data is highly skewed to the right. Although such data are subjected to transformations, extreme skewness to the right does non-significantly change (Agresti, 1997; Cameron et al. 1998, Dean and Lawless, 1989).

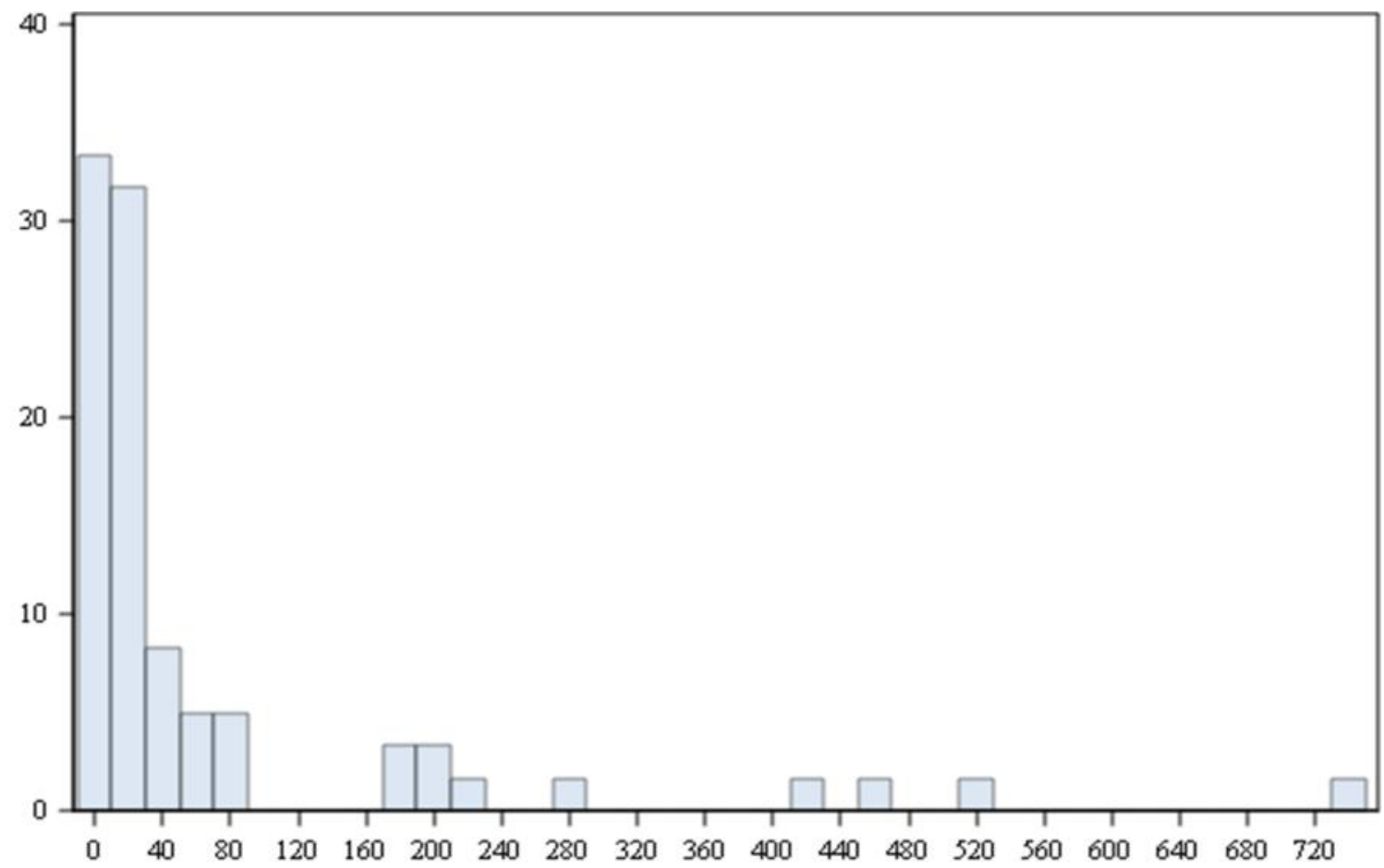

Fig. 2. Bird population density graph on Akdoğan Lake.

Goodness of fit criteria for Poisson and negative binomial regression are given in Table 3. The value of over-dispersion was obtained by dividing the deviance statistic into its own degrees of freedom. The value of over-dispersion in Poisson regression (33.827) was much larger than a value of 1.0 (Table 3 ). The value of over-dispersion in the negative binomial regression (1.598) was close to 1.0. The results of deviance compliance measure indicated a fairly large over-dispersion in the dependent variable and negative binomial regression was considered more appropriate. The estimated parameter values and standard errors for Poisson and negative binomial regression were given in Tables 4 and 5 .

Table 3. Goodness of fit criteria for Poisson and negative binomial regression models.

\begin{tabular}{lccc}
\hline Model & Df $^{* *}$ & Deviance statistics & Over-dispersion $^{* *}$ \\
\hline Poisson regression & 37 & 1251.5963 & 33.827 \\
Negative binomial regression & 37 & 59.1406 & 1.598
\end{tabular}

${ }^{*} \mathrm{Df}=$ Degree of freedom, ${ }^{* *}$ Deviance statistic $/ \mathrm{Df}$

The results of Poison regression reflected that according to Anseriformes order reference parameter, population increase and decrease in Bucerotiformes, Coraciiformes and Falconiformes $(p<0.05)$, 
Caprimulgiformes, Cuculiformes, Pelecaniformes, Strigiformes, Charadriiformes, Gruiformes and Passeriformes orders were statistically significant $(p<0.01)$ (Table 3). However, changes in population of Podicipediformes, Galliformes and Ciconiiformes orders were not statistically significant. Population changes in summer and autumn seasons were statistically significant $(p<0.01)$ based on spring reference parameter. Population changes in rocky $(p<0.05)$, meadow, marsh, wooded and open water surface areas were statistically significant $(p<0.01)$, when the reed area considered as reference parameter. An increase in the number of species and UTM squares significantly increased the population density $(p<0.01)$. The results of negative binomial regression indicated that population changes in the 12 order groups, according to the Anseriformes order reference parameter, were non-significant. However, the population change in the Gruiformes order was statistically significant $(p<0.01)$ (Table 4$)$.

Population changes in summer and autumn seasons were not statistically significant according to the spring reference parameter. When reed area was considered as the reference parameter; changes of population in open water surface, rocky, meadow, marsh and wooded areas were not statistically significant. The increase in the number of species and grids resulted in statistically significant increases in population density. Over-dispersion values of the dependent variable were quite high (Tables 4 and 5) which caused to the differences in the predictions of parameters and standard errors in both regression models. The interpretation of parameter estimates given for both regression models differed from linear regression (Tables 4 and 5). The Poisson regression and the negative binomial regression models need to be linearized using the log link function to determine the effect of each individual variable on the dependent variable.

One level of each independent variable is considered as the reference category in regression models on the basis of generalized linear models i.e Poisson and negative binomial (Luo and Qu, 2015; Yeşilova et al., 2016). The independent variables taken as the reference level were Anseriformes for order, spring for seasons, reed area, number of species and number of UTM squares for habitats.

Table 4. Values for Poisson regression model parameter estimates and standard error (std. error) obtained for Akdoğan (Hamurpet) Lakes.

\begin{tabular}{lcccccccc}
\hline \multicolumn{1}{c}{ Parameters } & \multicolumn{1}{c}{ Df Estimate } & $\begin{array}{c}\text { Standard } \\
\text { error }\end{array}$ & \multicolumn{2}{c}{$\begin{array}{c}\text { \%95 Wald confidence } \\
\text { interval }\end{array}$} & $\begin{array}{c}\text { Wald Chi-square } \\
\text { value }\end{array}$ & p-value & Exp. \\
\hline Intercept & 1 & 2.8032 & 0.0972 & 2.6126 & 2.9938 & 831.12 & 0.0001 & 16.497 \\
Bucerotiformes & 1 & -0.7054 & 0.2952 & -1.2840 & -0.1268 & 5.71 & 0.0169 & 0.493 \\
Caprimulgiforme & 1 & -2.6490 & 1.0053 & -4.6194 & -0.6786 & 6.94 & 0.0084 & 0.070 \\
Charadriiformes & 1 & 0.8218 & 0.0999 & 0.6259 & 1.0177 & 67.61 & 0.0001 & 2.274 \\
Ciconiiformes & 1 & -0.9399 & 0.5106 & -1.9406 & 0.0609 & 3.39 & 0.0657 & 0.391 \\
Coraciiformes & 1 & 0.3496 & 0.1459 & 0.0636 & 0.6356 & 5.74 & 0.0166 & 1.418 \\
Cuculiformes & 1 & -1.9779 & 0.5861 & -3.1267 & -0.8290 & 11.39 & 0.0007 & 0.138 \\
Falconiformes & 1 & 0.2452 & 0.1082 & 0.0330 & 0.4573 & 5.13 & 0.0235 & 1.277 \\
Gruiformes & 1 & 2.1626 & 0.0994 & 1.9678 & 2.3574 & 473.35 & 0.0001 & 8.693 \\
Galliformes & 1 & 0.1594 & 0.1852 & -0.2037 & 0.5224 & 0.74 & 0.3896 & 1.172 \\
Passeriformes & 1 & 0.5269 & 0.1116 & 0.3083 & 0.7456 & 22.31 & 0.0001 & 1.693 \\
Pelecaniformes & 1 & -0.8931 & 0.2612 & -1.4049 & -0.3812 & 11.69 & 0.0006 & 0.409 \\
Podicipediformes & 1 & 0.1250 & 0.1281 & -0.1261 & 0.3760 & 0.95 & 0.3292 & 1.133 \\
Strigiformes & 1 & -2.1834 & 0.7149 & -3.5847 & -0.7822 & 9.33 & 0.0023 & 0.112 \\
Number of & 1 & 0.0268 & 0.0041 & 0.0187 & 0.0349 & 41.81 & 0.0001 & 1.027 \\
species & 1 & -0.6521 & 0.0472 & -0.7446 & -0.5595 & 190.84 & 0.0001 & 0.520 \\
Summer & 1 & -0.1999 & 0.0445 & -0.2871 & -0.1127 & 20.19 & 0.0001 & 0.818 \\
Autumn & 1 & 0.1858 & 0.0780 & 0.0328 & 0.3387 & 5.67 & 0.0173 & 1.204 \\
Rocky area & 1 & & & & & & \\
Open surface & 1 & 0.4505 & 0.0614 & 0.3301 & 0.5709 & 53.78 & 0.0001 & 1.569 \\
water & 1 & -0.3171 & 0.1117 & -0.5360 & -0.0982 & 8.06 & 0.0045 & 0.728 \\
Swamp ares & 1 & 0.4104 & 0.0800 & 0.2535 & 0.5672 & 26.30 & 0.0001 & 1.507 \\
Grasslands & 1 & -0.6486 & 0.1902 & -1.0213 & -0.2758 & 11.63 & 0.0006 & 0.522 \\
Mixed forests & 1 & 0.0607 & 0.0028 & 0.0552 & 0.0662 & 465.62 & 0.0001 & 1.062 \\
Grid & & & & & &
\end{tabular}

$\mathrm{Df}=$ Degree of freedom 
Table 5. Values for negative binomial regression model parameter estimates and standard error obtained for Akdoğan (Hamurpet) Lakes.

\begin{tabular}{lcccccccc}
\hline \multicolumn{1}{c}{ Parameters } & \multicolumn{1}{c}{ Df } & Estimate Standard error & \multicolumn{2}{c}{$\begin{array}{c}\text { \%95 Wald confidence } \\
\text { interval }\end{array}$} & $\begin{array}{c}\text { Wald Chi-square } \\
\text { value }\end{array}$ & p-value & Exp. \\
\hline Intercept & 1 & 2.1354 & 0.3839 & 1.3830 & 2.8878 & 30.94 & 0.0001 & 8.460 \\
Bucerotiformes & 1 & -0.2968 & 0.7015 & -1.6716 & 1.0781 & 0.18 & 0.6722 & 0.743 \\
Caprimulgiformes & 1 & -2.4607 & 1.2786 & -4.9667 & 0.0452 & 3.70 & 0.0543 & 0.085 \\
Charadriiformes & 1 & 0.6892 & 0.3986 & -0.0920 & 1.4704 & 2.99 & 0.0838 & 1.992 \\
Ciconiiformes & 1 & -0.8273 & 0.9175 & -2.6256 & 0.9709 & 0.81 & 0.3672 & 0.437 \\
Coraciiformes & 1 & 0.3993 & 0.5645 & -0.7070 & 1.5056 & 0.50 & 0.4793 & 1.490 \\
Cuculiformes & 1 & -0.8432 & 1.0150 & -2.8325 & 1.1461 & 0.69 & 0.4061 & 0.430 \\
Falconiformes & 1 & -0.1163 & 0.4218 & -0.9430 & 0.7104 & 0.08 & 0.7828 & 0.890 \\
Gruiformes & 1 & 2.4808 & 0.4882 & 1.5240 & 3.4376 & 25.82 & 0.0001 & 11.950 \\
Galliformes & 1 & 0.9451 & 0.6955 & -0.4179 & 2.3082 & 1.85 & 0.1741 & 2.573 \\
Passeriformes & 1 & -0.4909 & 0.4666 & -1.4054 & 0.4237 & 1.11 & 0.2928 & 0.612 \\
Pelecaniformes & 1 & -0.8325 & 0.5804 & -1.9701 & 0.3051 & 2.06 & 0.1515 & 0.434 \\
Podicipediformes & 1 & 0.4339 & 0.4577 & -0.4631 & 1.3309 & 0.90 & 0.3430 & 1.543 \\
Strigiformes & 1 & -1.1291 & 1.0992 & -3.2834 & 1.0252 & 1.06 & 0.3043 & 0.323 \\
Number of & 1 & 0.1952 & 0.0446 & 0.1077 & 0.2827 & 19.11 & 0.0001 & 1.215 \\
species & 1 & -0.4204 & 0.2638 & -0.9374 & 0.0965 & 2.54 & 0.1110 & 0.656 \\
Summer & 1 & -0.1195 & 0.3276 & -0.7616 & 0.5225 & 0.13 & 0.7152 & 0.887 \\
Autumn & 1 & -0.4430 & 0.4321 & -1.2898 & 0.4039 & 1.05 & 0.3053 & 0.642 \\
Rocky area & 1 & 0.5664 & 0.3423 & -0.1045 & 1.2373 & 2.74 & 0.0980 & 1.761 \\
Open surface & 1 & -0.2681 & 0.4508 & -1.1515 & 0.6154 & 0.35 & 0.5521 & 0.764 \\
water & 1 & 0.4964 & 0.4307 & -0.3478 & 1.3407 & 1.33 & 0.2491 & 1.642 \\
Swamp area & 1 & -0.1439 & 0.5660 & -1.2532 & 0.9654 & 0.06 & 0.7993 & 0.856 \\
Grasslands & 1 & 0.0541 & 0.0211 & 0.0128 & 0.0955 & 6.59 & 0.0102 & 1.056 \\
Mixed forests & Grid & & & & & & &
\end{tabular}

$\mathrm{Df}=$ Degree of freedom

The results for the effects of the independent variables on bird populations were shown in Tables 4 and 5. However, there were different levels of independent variables such as orders (Anseriformes, Bucerotiformes, Caprimulgiformes, Charadriiformes, Ciconiiformes, Coraciiformes, Cuculiformes, Falconiformes, Gruiformes, Galliformes, Passeriformes, Pelecaniformes, Podicipediformes, Strigiformes), number of species, number of UTM squares used, seasons (Spring, Summer and Autumn), and habitats (open water surface, rocky, marshy, reed, wooded and meadow areas). Therefore, each independent variable level was separately tested to understand the importance of particular variable on bird populations.

As previously well-documented, seasonality (Caula et al., 2008; Chen et al., 2019; Gomes et al., 2017; Girma et al., 2017; Katuwal et al., 2016) and habitat (Caula et al., 2008; Chen et al., 2018; Chen et al., 2019; Durmuş et al., 2018; Girma et al., 2017) influence the species richness and population size. The present results of the study are consistent with the previous reports given above.

Negative binomial regression was accepted as the best regression model according to compliance measures and the results of Table 5 were interpreted in this respect. Population changes among order groups were non-significant, while population change increased by 11.95 -fold when Gruiformes order was considered as the reference parameter $(\mathrm{p}<0.01)$. One unit increase in species and UTM square numbers caused to 1.215 and 1.056-fold population increases, respectively. Population changes between seasons and habitats were not statistically significant.

Conclusion: Deviance statistics caused to a considerable over-dispersion in the dependent variable. Therefore, the use of negative binomial regression was considered to be more appropriate the in evaluation of parameters. The results of parameter estimates obtained by Poisson and negative binomial regression were different from each other.

Bird populations have changed depending on seasons, orders and habitat types. Reeds and marshy areas that cover very little space around the lake become very active habitats at spring in terms of ornithology. These habitats are suitable for both breeding and feeding, many different species of birds breed and meet their nutritional demands. However, these areas get dry with decreasing 
precipitation and increasing temperature. This situation has been a significant impact on habitat preferences of birds. Population density in reed and marsh areas during breeding period was high, but population density in these habitats decreased in summer. Population density in summer season increased on open water surface and meadow areas. Differences in population intensities were observed between seasons but changes were not statistically significant. When spring was considered as the reference level, the number of bird populations decreased by $35 \%(p>0.05)$ and $11 \%(p>0.05)$ in summer and autumn seasons, respectively. The population change in order groups was significant $(\mathrm{p}<0.01)$ only based on the Gruiformes order reference level. The populations of Common coot (Fulica atra) species caused significant population increase compared to other groups due to the concentrated population in every season. Existence of different population tendency among the order results from the differences in vital activities and habitat preferences between species to species.

Acknowledgement: This study is a part of the $\mathrm{PhD}$ thesis project (FDK-2016-5176) funded by Directorate of Scientific Research Projects of Yuzuncu Y1l University, Van, Turkey.

\section{REFERENCES}

Adızel, Ö., A. Durmuş, and İ. Kiziroglu, (2010). Preliminary study on newly detected yayliyaka marshes in the Lake Van Basin, Turkey. The J. Anim. Plant Sc., 20(4): 286-292.

Agresti, A., (1997). Categorical Data Analysis. John and Wiley \& Sons, Incorporation, New Jersey, Canada.

Aksan, Ş., İ. Özdemir, and İ. Oğurlu, (2014). Modeling the distributions of some wild mammalian species in Gölcük Natural Park/Turkey. Biological Diversity and Conservation. 7(1): 115.

Austin, J., S. Slattery, and R.G. Clarke (2014). Waterfowl populations of conservation concern: learning from diverse challenges, models and conservation strategies. Wildfowl, 4, 470-497.

Beerens, J.M., D.E. Gawlik, G. Herring, and M.I. Cook, (2011). Dynamic habitat selection by two wading bird species with divergent foraging strategies in a seasonally fluctuating wetland. The Auk. 128(4): 651-662.

Bibby, C.J., D.N. Burgess, A.D. Hill, and S. Mustoe, (2000). Bird Census Techniques, Second Edition, Academic Press, ISBN 0-12-095831-7, London, United Kingdom. 86

Bolker, B.M., M.E. Brooks, C.J. Clark, S.W. Geange, J.R. Poulsen, M.H. Stevens, J.S. Handand, and
S. White, (2008). Generalized linear mixed models: a practical guide forecology and evolution. Trends Ecol. Evol., 24, 127-135.

Boveng, P.L., J.L. Bengtson, D.E. Withrow, J.C. Cesarone, M.A. Simpkins, K.J. Frost, and J.J. Burns, (2003). The abundance of harbor seals in the Gulf of Alaska. Mar. Mam. Sci., 19, 111127.

Cameron, A.C., and P.K. Trivedi, (1998). Regression Analysis of Count Data. Cambridge University Press, NY.

Caula, S., P. Marty, and J.L. Martin, (2008). Seasonal variation in species composition of an urban bird community in Mediterranean France. Landscape Urban Plan., 87(1), 1-9.

Çelik, E., and A. Durmuş, (2017). Determining the Seasonal Ornithological Potential of the Dönemeç (Engil) Delta and Generate the Digital Maps Using Geographical Information Systems (GIS). Iğdır Üniversitesi Fen Bilimleri Enstitüsü Dergisi, 7(3): 73-78.

Che, X., D. Chen, M. Zhang, Q. Quan, A.P. Møller, and F. Zou, (2019). Seasonal dynamics of waterbird assembly mechanisms revealed by patterns in phylogenetic and functional diversity in a subtropical wetland. Biotropica, 51(3), 421-431.

Che, X., M. Zhang, Y. Zhao, Q. Zhang, Q. Quan, A. Møller, and F. Zou, (2018). Phylogenetic and functional structure of wintering waterbird communities associated with ecological differences. Sci. Rep., 8(1), 1232.

Czado, C., V. Erhardt, A. Min, and S. Wagner, (2007). Dispersion and zero-inflation level applied to patent outsourcing rates Zero-inflated generalized Poisson models with regression effects on the mean. Statistical Modelling, 7, 125-153.

Dalrymple, M.L., I.L. Hudson, and R.P.K. Ford, (2003). Finite mixture, zero-inflated poisson and hurdle models with application to SIDS. Comput Stat Data An., 41, 491-504

Dean, C., and J.F. Lawless, (1989). Tests for Detecting Over-dispersion in Poisson Regression Models. JASA., 84(406): 467-472.

Durmuş, A., A. Yeşilova, E. Çelik, and R. Kara, (2018). Using Poisson and Negative Binomial Regression Models on Birds Population in Dönemeç Delta. Yuzuncu Yil University J. Agricultural Sciences, 28(1):78-85.

Famoye, F., and P.S. Karan, (2006). Zero- inflated generalized poisson regression model with an application to domestic violence data. Data Sci. J., 5, 117-130.

Frost, K.J., L.F. Lowry, and J.M. Ver Hoef, (1999). Monitoring the trend of harbor seals in Prince 
William Sound, Alaska, after the Exxon Valdez oil spill. Mar. Mam. Sci., 15, 494-506.

Geldiay, R., and A. Kocataş, (1983). General Ecology. Ege University Science Faculty Books Series No: 65, p. 282

Girma, Z., Y. Mamo, G. Mengesha, A. Verma, and T. Asfaw, (2017). Seasonal abundance and habitat use of bird species in and around Wondo Genet Forest, south central Ethiopia. Ecol. Evol., 7(10):3397-3405

Gomes, M., J.E. Rabaça, C. Godinho, and J. A. Ramos, (2017). Seasonal variation in bird species richness and abundance in riparian galleries in Southern Portugal. Acta Ornithol.,52(1), 69-80.

Hilbe, J.M., (2007). Negative Binomial Regression. Cambridge, U.K.

Joseph, L.N., C. Elkin, T.G. Martin, and H.P. Possingham, (2009). Modeling abundance using N-mixture models: the importance of considering ecological mechanisms. Ecol. Appl., 19(3): 631-642.

Katuwal, H.B., K. Basnet, B. Khanal, S. Devkota, S.K. Rai, J.P. Gajurel, and M.P. Nobis, (2016). Seasonal changes in bird species and feeding guilds along elevational gradients of the Central Himalayas, Nepal. PLoS ONE , 11(7), $\mathrm{e} 0158362$.

Kiziroğlu, İ., (2001). Birds, Our Flying Friends, Chapter 6. Ecological Potpourri, Takav Printing ouse. Pub. Inc. Ankara. 391.

Kiziroğlu, İ., (2008). Birds of Turkey. Species List, and Red List of Birds of Turkey. Hacettepe University, Environmental Education, Bird Investigations and Public Relations Center, Ankara. 86.

Leisch, F., (2004). A general framework for finite mixture models and latent class regression in $\mathrm{R}$. J. Stat. Softw., 11(8): 1-18.

Lindén, A., and S. Mäntyniemi, (2011). Using the negative binomial distribution to model overdispersion in ecological count data. Ecology, 92(7): 1414-1421.

Luo, J., and Y. Qu, (2015). Estimation of group means when adjusting for covariates in generalized linear models. Pharm Stat., 14(1): 56-62.

Mathews, E.A., and G.W. Pendleton, (2006). Declines in harbor seal (Phoca vitulina) numbers in Glacier Bay National Park, Alaska, 1992-2002. Mar. Mam. Sci., 22, 167-189.

Milsom, T.P., S.D. Langton, W.K. Parkin, S. Peel, J.D. Bishop, J.D. Hart, and N.P. Moore, (2000). Habitat Models of Bird Species' Distribution: an Aid to The Management of Coastal Grazing Marshes. J. Appl. Ecol., 37, 706-727.

Muthén, L.K., and B. Muthén, (2006). Mplus: User's guide. Los Angeles, CA: Muthén \& Muthén
O’Hara, R.B., (2005). Species richness estimators: How many species can dance on the head of a pin? J. Anim. Ecol., 74, 375-386.

O'Hara, R.B., (2009). How to make up models add up-a primer on GLMMs. Ann. Zool. Fenn., 46, 124 137.

O'Hara, R.B., and D.J. Kotze, (2010). Do not logtransform count data. Methods Ecol. Evol., 1, $118-122$.

Onmuş, O., (2008). Monitoring of the nesting areas of water bird species breeding in Gediz Delta and the management of these colonies (doctoral thesis, unpublished). Ege Univ. Science. Inst. İzmir, Turkey.

Özkan, K., (2009). A suggestion on appropriate inventory method for analytical evaluation in wildlife ecology. Süleyman Demirel University, J. Forestry, Series: A, Issue 2, 160-169.

Rékási, J., L. Rozsa, and B.J. Kiss, (1997). Patterns in the distribution of avian lice (Phthiraptera: Amblycera, Ischnocera). J. Avian Biol., 28(2):150-156.

Ridout, M., G.B.D. Clarice, and H. John, (1998). Models for count data with many zeros. International Biometric Conference. Cape Town.

SAS, (2014). SAS/STAT Software:Hangen and Enhanced. SAS Inst Inc, USA.

SAS, (2015). SAS/Stat Software Hangen and Enhanced, SAS Institute Incorporation, USA.

Seoane, J., J. Bustamante, and R. Diaz-Delgado, (2004). Competing roles for landscape, vegetation, topography and climate in predictive models of bird distribution. Ecol. Model., 171(3): 209-222.

Small, R.J., G.W. Pendleton, and K.W. Pitcher, (2003). Trends in abundance of Alaska harbor seals, 1983-2002. Mar. Mam. Sci., 19(2):344-362.

Stanevičius, V., (2002). Nest-site selection by coot and great-crested grebe in relation to structure of halophytes. Acta Zool. Lituan., 12(3): 265-275.

Ver Hoef, J.M., and P.L. Boveng, (2007). Quasi Poisson vs. negative binomial regression: how should we model overdispersed count data?. Ecology. 88 (11), 2766-2772.

Wang, P., and M.L. Putterman, (1998). Mixed logistic regression models. J. Agr. Biol. Envir. St., 3(2): 175-200.

Wang, P., M.L. Puterman, I.M. Cockburn, and N. Le, (1996). Mixed poisson regression models with covariate dependent rates. Biometrics, 52(2): 381-400.

Wedderburn, R.W.M., (1974). Quasi-likelihood functions, generalized linear models, and the Gauss-Newton method. Biometrika, 61(3): 439447.

White, G.C., and R.E. Bennetts, (1996). Analysis of frequency count data using the negative 
binomial distribution. Ecology, 77(8): 25492557.

Yeşilova, A., B. Kaydan, and Y. Kaya, (2010). Modeling insect-egg data with excess zeros using zeroinflated regression models. Hacet. J. Math. Stat., 39(2): 273-282.

Yeşilova, A., M.S. Özgökçe, R. Atlıhan, Ş. Polat Yıldız, İ. Karaca, and G. Ser, (2016). Modeling of the arthropod population densities in the coastal band of Lake Van using mixture poison regression. Fresenius Environ. Bull., 25, 17681778.

Yoccoz, N.G., J.D. Nichols, and T. Boulinier, (2001). Monitoring of biological diversity in space and time. Trends Ecol. Evol., 16(8): 446-453.

Yuan, Y., G. Zeng, J. Liang, X. Li, Z. Li, C. Zhang, and $\mathrm{X}$. Yu, (2014). Effects of landscape structure, habitat and human disturbance on birds: a case study in East Dongting Lake wetland. Ecol. Eng ., 67, 67-75. 